\title{
In vitro antibacterial activity in seed extracts of Manilkara zapota, Anona squamosa, and Tamarindus indica
}

\author{
Vijay Kothari and Sriram Seshadri* \\ Department of Biochemistry \& Biotechnology, Institute of Science \\ Nirma University of Science \& Technology, S G Highway, Ahmedabad-382481, Gujarat, India
}

\begin{abstract}
Extracts prepared from seeds of Manilkara zapota, Anona squamosa, and Tamarindus indica were screened for their antibacterial activity by disc diffusion and broth dilution methods. Acetone and methanol extracts of T. indica seeds were found active against both gram-positive and gram-negative organisms. MIC values of potent extracts against susceptible organisms ranged from 53-380 $\mu \mathrm{g} / \mathrm{mL}$. Methanol extract of T. indica and acetone extract of $M$. zapota seeds were found to be bactericidal.
\end{abstract}

Key terms: Tamarindus indica; Manilkara zapota; in vitro activity, bactericidal activity.

\section{INTRODUCTION}

Natural products have been a significant source of commercial medicines and drug leads. Nearly $61 \%$ of drugs introduced worldwide can be traced to natural products (Cseke et al., 2004). Screening of crude plant extracts paves the way for discovery of novel bioactive compounds and elucidation of their structures can open the door for new synthetic preparations. Pure bioactive compounds can be administered in reproducible, accurate doses for particular therapeutic purposes (Colegate and Molyneux, 2007). Seed extracts have been reported by several researchers for their antimicrobial activity (Nascimento et al., 2000).

The present study was aimed at screening various extracts of three different plant seeds viz. Manilkara zapota L (Sapotaceae), Anona Squamosa L (Annonanceae), and Tamarindus indica L (Leguminosae) for their antibacterial activity. Extracts of stem, bark, and leaves of T. indica have been reported for their antibacterial (Doughari, 2006), as well as antifungal activity (Tyagi and Bohra, 2003). Satish et al., (2007) has reported antifungal activity of $M$. zapota extracts.

\section{MATERIALS AND METHODS}

Seeds of the three plants M. zapota, A. squamosa, and T. indica were procured from local market in the city of Ahmedabad. They were authenticated for their unambiguous identity by Prof. Y. T. Jasrai, Head of Botany Dept., Gujarat University, Ahmedabad.

Seeds were extracted in four different solvents
(Merck, Mumbai, India) - methanol, ethanol (50\%), acetone, and chloroform, using the microwave assisted extraction (MAE) method (Kothari et al., 2009). Dry seed powder was soaked into the solvent in a ratio of 1:50, and subjected to microwave heating (Electrolux EM30EC90SS) at $720 \mathrm{~W}$. Total heating time was kept 90, 70, 120, and 180 second for methanol, ethanol, acetone, and chloroform respectively, with intermittent cooling. This was followed by centrifugation (at 10,000 rpm for 15 min.), and filtration with Whatman paper \# 1 (Whatman International Ltd., Maidstone, England). Solvent was evaporated from the filtered extract and then the dried extracts were reconstituted in: (i) their respective solvents for disc diffusion assay, and (ii) dimethyl sulfoxide (DMSO) for broth dilution assay. Reconstituted extracts were stored under refrigeration for further use. Extraction efficiency was calculated as the percentage weight of the starting dried plant material. Extraction efficiency ranged from $2-15 \%$, with highest $(15 \%)$ being in case of acetone extract of $A$. squamosa seeds.

Test organisms used were Staphylococcus aureus MTCC 737, Streptococcus pyogenes MTCC 442, Staphylococcus epidermidis MTCC 435, Escherichia coli MTCC 723, Aeromonas hydrophila MTCC 1739, Salmonella paratyphi A, Shigella flexneri MTCC 1457, Vibrio cholerae MTCC 3906, and Pseudomonas oleovorans MTCC 617. S. paratyphi A was procured from Department of Microbiology, Gujarat University, Ahmedabad, while the rest were obtained from Microbial Type Culture Collection (MTCC), Chandigarh.

Disc diffusion assay (DDA) was performed

\footnotetext{
* Corresponding Author: Dr. Sriram Seshadri Head, Department of Biochemistry \& Biotechnology, Institute of Science, Nirma University of Science \& Technology, Sarkhej Gandhinagar Highway, Ahmedabad-382481, India. Ph: +91-02717-241901; Extn.-627, Fax: +91-2717-241916 Email: sriram.seshadri@nirmauni.ac.in, sriramsjpr@gmail.com
} 
by Kirby-Bauer method as per NCCLS guidelines (Jorgensen and Turnidge, 2003). $500 \mu \mathrm{L}$ of inoculum (adjusted to $0.5 \mathrm{McF}$ arland standard) was spread on surface of Muller-Hinton agar medium (HiMedia, Mumbai, India). Sterile discs (6 $\mathrm{mm}$ diameter) made of Whatman paper \# 1 were dipped into the test extract and were put onto the agar surface after complete drying. Discs dipped into pure solvents were applied as negative control. Commercially available discs of either streptomycin or Ofloxacin (HiMedia) served as positive control. Plates were then incubated at $35^{\circ} \mathrm{C}$ for $24 \mathrm{~h}$. After incubation plates were observed for zones of inhibition, and their diameter were measured. Studies were performed in triplicates.

MIC (minimum inhibitory concentration) determination was carried out using microbroth dilution method as per NCCLS guidelines (Jorgensen and Turnidge, 2003). Assay was performed in 96-well microtitre plates. Total volume of the assay system in each well was kept $200 \mu \mathrm{L}$. Cation-adjusted Muller-Hinton broth (HiMedia) was used as growth medium. Inoculum density of the test organisms was adjusted to that of $0.5 \mathrm{McF}$ arland standard. Broth was dispensed into wells of microtitre plate followed by addition of test extract and inoculum. Extracts (reconstituted in DMSO) were serially diluted into each of the wells. A DMSO control was included in all assays. Gentamicin (HiMedia) served as a positive control. Plates were incubated at $35^{\circ} \mathrm{C}$ for $16-20 \mathrm{~h}$, before being read at $655 \mathrm{~nm}$ in a plate reader (BIORAD 680). MIC was recorded as the lowest concentration at which no growth was observed. All MICs were determined on three independent occasions. Concentration at which growth was inhibited by $50 \%$ was recorded as $\mathrm{IC}_{50}$ value.
After reading the plates for MIC, subculturing was done on nutrient agar from the wells showing no growth. After incubation the concentration, which killed $99.9 \%$ of the population (compared with the original inoculum), was reported as MBC (minimum bactericidal concentration). Total activity (mL/g) was calculated as (Eloff, 2004): the amount extracted from $1 \mathrm{~g}(\mathrm{mg}) / \mathrm{MIC}(\mathrm{mg} / \mathrm{mL})$.

Active extracts were tested for presence of alkaloids, flavones, phenolics, and flavonoids (Wagner et al., 1983; Borgio et al., 2008).

\section{RESULTS AND DISCUSSION}

When all the extracts prepared were screened for antibacterial activity through DDA (table 1), $S$. flexneri, S. paratyphi A, V. cholerae, and S. epidermidis were found to be susceptible to one or more of the test extracts. All other strains tested were not susceptible to any of the extracts. $V$. cholerae exhibited susceptibility to five different extracts. Extracts prepared in ethanol and chloroform exerted no activity against any of the organism tested.

Extracts that exerted activity in DDA were further subjected to MIC and MBC determination (table 2). Methanolic extract of T. indica seeds and acetone extract of $M$. zapota seeds were found to be bactericidal, each against at least 2 test organisms. The lowest MIC value $(53 \mu \mathrm{g} / \mathrm{mL})$ was recorded for methanolic extract of $T$. indica seeds against $S$. epidermidis. In terms of MIC values. This extract was found to be 6.22, and 1.56 times more potent than the acetone extract of the same seed against $S$. epidermidis and S. paratyphi A, respectively.

In some cases, very small changes in concentration of the test extract were found to affect growth of the organism significantly. For example,

Table 1

Disc diffusion assay of different extracts

\begin{tabular}{|c|c|c|c|c|c|c|c|c|}
\hline \multirow[t]{3}{*}{ Organism } & \multicolumn{8}{|c|}{ Zone of Inhibition $(\mathrm{mm})($ Mean $\pm \mathrm{SD})$} \\
\hline & \multicolumn{2}{|c|}{ M. zapota } & \multicolumn{2}{|c|}{ A. squamosa } & \multicolumn{2}{|c|}{ T. indica } & \multicolumn{2}{|c|}{ Positive control } \\
\hline & $\mathrm{M}$ & $\mathrm{A}$ & $\mathrm{M}$ & $\mathrm{A}$ & $\mathrm{M}$ & $\mathrm{A}$ & S & $\mathrm{O}$ \\
\hline A. hydrophila & FI & 0 & 0 & 0 & 0 & 0 & $18 \pm 2$ & - \\
\hline S. flexneri & $14 \pm 4.14$ & $9 \pm 1$ & 0 & $8 \pm 0.57$ & - & - & - & $31 \pm 2.4$ \\
\hline S. paratyphi A & $15 \pm 4.96$ & 0 & 0 & 0 & $15 \pm 4.61$ & $16 \pm 2.88$ & $22 \pm 1$ & - \\
\hline V. chlorae & $14 \pm 1$ & $17 \pm 1.52$ & $16 \pm 1.52$ & $18 \pm 4.04$ & 0 & $9 \pm 1.15$ & $20 \pm 2.2$ & $27 \pm 1.4$ \\
\hline S. epidermidis & - & - & - & - & $10 \pm 0.57$ & $12 \pm 1.52$ & $19 \pm 1.8$ & - \\
\hline
\end{tabular}

S: Streptomycin (10 $\mu \mathrm{g} /$ disc); O:Ofloxacin (5 $\mu \mathrm{g} /$ disc); M: Methanol; A: Acetone

FI: Faint inhibition without clear zone

\#These extracts exerted no activity against E. coli, P. oleovorans, S. aureus, and S. pyogenes. 
Table 2

Results of broth dilution assay of different extracts

\begin{tabular}{|c|c|c|c|c|c|c|}
\hline Seed & Solvent & Organism & $\mathrm{IC}_{50}(\mu \mathrm{g} / \mathrm{ml})$ & $\mathrm{MIC}(\mu \mathrm{g} / \mathrm{ml})$ & $\mathrm{MBC}(\mu \mathrm{g} / \mathrm{ml})$ & Total activity $(\mathrm{mL} / \mathrm{g})$ \\
\hline \multirow[t]{4}{*}{ M. zapota } & Methanol & S. flexneri & 945 & $>1497$ & - & - \\
\hline & & V. cholerae & 950 & $>1497$ & - & - \\
\hline & Acetone & V. cholerae & 93.75 & 216.5 & 216.5 & 369.5 \\
\hline & & P. oleovorans & 317 & 323 & 323 & 247.6 \\
\hline \multirow[t]{2}{*}{ A. squamosa } & Methanol & V. cholerae & $>900$ & $>900$ & - & - \\
\hline & Acetone & V. cholerae & 1310 & $>1800$ & - & - \\
\hline \multirow[t]{4}{*}{ T. indica } & Methanol & S. paratyphi A & $<240$ & 242.5 & 242.8 & 536.1 \\
\hline & & S. epidermidis & $<50$ & 53 & 56 & 245.8 \\
\hline & Acetone & S. paratyphi A & 375 & 380 & $>400$ & 52.63 \\
\hline & & S. epidermidis & $<300$ & 330 & $>350$ & 60.6 \\
\hline
\end{tabular}

an increase of as little as $0.5 \mu \mathrm{g} / \mathrm{mL}$ in concentration (from 242.5 to $243 \mu \mathrm{g} / \mathrm{mL}$ ) of methanolic extract of T. indica seeds caused $14 \%$ higher inhibition (from 82 to $96 \%$; as compared to the DMSO control) of $S$. paratyphi $A$. Similarly, acetone extract of $M$. zapota seeds caused 18\% higher inhibition (from 82 to $100 \%)$ of P. oleovorans, when its concentration was raised by only $2 \mu \mathrm{g} / \mathrm{mL}$ (from 323 to $325 \mu \mathrm{g} / \mathrm{mL}$ ). The same extract caused an increase in inhibition of $V$. cholerae by $18 \%$ (from 61 to $79 \%$ ), when concentration was raised by just $1 \mu \mathrm{g} / \mathrm{mL}$ (from 215 to $216 \mu \mathrm{g} / \mathrm{mL}$ ). These observations emphasize the need for testing the extracts in very narrow ranges for accurate determination of MIC values.

Total activity of potent extracts was also calculated and was found to be highest $(536.1 \mathrm{~mL} / \mathrm{g})$ in case of methanolic extract of $T$. indica seeds against $S$. paratyphi $A$. Total activity is a measure of the amount of material extracted from a plant in relation to the MIC of the extract, fraction or isolated compound. It indicates the degree to which the active fractions or compounds present in $1 \mathrm{~g}$ can be diluted and still inhibit growth of the test organism (Eloff, 2004). Total activity was found to have a strong positive linear correlation $(r=0.973)$ with extraction efficiency.

Phytochemical tests indicated presence of phenols and flavones in methanolic and acetone extracts of $T$. indica seeds. Acetone extract of $M$. zapota seeds tested positive for alkaloids, phenols, and flavonoids.

\section{CONCLUSION}

Among various extracts tested, three (acetone extracts of M. zapota and T. indica, and methanolic extract of $T$. indica) were found to have significant antibacterial activity. Both extracts of $T$. indica seeds can be said to have a broad spectrum of activity, as they are active against gram-positive, as well as gram-negative bacteria. These extracts should be further investigated for identification of active constituent(s). Active constituent(s) once separated can be subjected to compatible techniques such as IR and NMR spectroscopy for structural studies.

\section{ACKNOWLEDGEMENT}

Authors thank Nirma Education \& Research Foundation (NERF) for the financial assistance, Prof. Y. T. Jasrai (Botany Dept., Gujarat University) for seed identification and Prof. S. R. Dave (Microbiology Dept., Gujarat University) for providing one of the test organisms.

\section{REFERENCES}

BORGIO JF, THORAT PK, LONKAR AD (2008) Antimycotic and antibacterial activities of Gynandropis pentaphylla DC extracts and its phytochemical studies. The Int J Microbiol 5: 1-14.

COLEGATE SM, MOLYNEUX RJ (2007) Bioactive natural products. In: Detection, Isolation, and Structural Determination. CRC press. pp: 1-9.

CSEKE L, KAUFMAN P, PODILA G, TSAI C (2004) Handbook of Molecular and Cellular Methods in Biology and Medicine. 2 nd ed. Florida: CRC press.

DOUGHARI JH (2006) Antimicrobial activity of Tamarindus indica Linn. Tropical J Pharma Res 5: 597-603.

ELOFF JN (2004) Quantifying the bioactivity of plant extracts during screening and bioassay-guided fractionation. Phytomed 11: 370-371

JORGENSEN JH, TURNIDGE JD (2003) Susceptibility test methods: Dilution and disk diffusion methods. In: 
MURRAY PR (ed) Manual of Clinical Microbiology. 8th ed. New York: ASM International. pp:1108-1127.

KOTHARI VO, PUNJABI AB, GUPTA SR (2009) Optimization of microwave assisted extraction of Anona squamosa seeds. The Icfai Univ J Life Sci 3: 55-60.

NASCIMENTO GG, LOCATELLI LJ, FREITAS PC, SILVA GL (2000) Antibacterial activity of plant extracts and phytochemicals on antibiotic resistant bacteria. Braz J Microbiol 31: 247-256.
SATISH S, MOHAN DC, RANHAVENDRA MP, RAVEESHA KA (2007) Antifungal activity of some plant extracts against important seed borne pathogens of Aspergillus sp. J Agri Tech 3:109-119.

TYAGI N, BOHRA A (2003) In vitro study of antifungal activity of Tamarindus indica against Aspergillus flavus and Fusarium oxysporum. In Fruits for the Future (1 $1^{\text {st }}$ edn):12-25.

WAGNER H, BLADT S, ZGAINSKI E (1983) Plant Drug Analysis. 2 nd ed. Berlin: Springer. 